\title{
CARACTERIZAÇÃO MOLECULAR E DIVERSIDADE GENÉTICA DE DIFERENTES VARIEDADES DE ABACATE POR MARCADORES MICROSSATÉLITES ${ }^{1}$
}

\author{
ANTONIO BALDO GERALDO MARTINS ${ }^{2}$, MARIA GABRIELA FONTANETTI RODRIGUES ${ }^{3}$, \\ DEISE REIS DE PAULA ${ }^{4}$, HÉLIO SANDOVAL JUNQUEIRA MENDES 5 , \\ FLÁVIO CESE ARANTES ${ }^{6}$, CRISTINA LACERDA SOARES PETRAROLHA SILVA ${ }^{7}$
}

RESUMO - Pertencente à família Lauraceae, o abacateiro compreende três raças hortícolas: antilhana, guatemalense e mexicana. Os marcadores moleculares são uma ferramenta rápida e eficaz para estudos genômicos, uma vez que detectam o polimorfismo diretamente ao nível do DNA e não sofrem qualquer tipo de influência ambiental. Com base nesse polimorfismo, é possível fazer inferências sobre as relações entre o genótipo e o fenótipo dos indivíduos, o que, em última análise, permite aumentar a eficiência dos programas de melhoramento. Diante o exposto, o objetivo foi investigar a diversidade genética entre sete variedades de abacate a partir de 5 lócus de marcadores moleculares microssatélites (SSR). Nas amostras de abacateiros avaliadas, encontrou-se um total de 18 alelos, com uma média de 3,6 alelos por lócus. O dendrograma gerado a partir de análise de agrupamento UPGMA agrupou, separadamente do resto dos genótipos, a cultivar Geada da raça Antilhana, possivelmente por esta variedade ser uma raça pura, e o restante foi agrupado em dois grandes grupos das raças, a Guatemalense e a Mexicana. Os genótipos das sete variedades de abacate apresentam diversidade genética nos cinco lócus de marcadores moleculares microssatélites (SSR) avaliados, o que indica que são materiais promissores para utilização em futuros programas de melhoramento.

Temos para Indexação: Persea americana, SSR, fingerprinting, banco de germoplasma.

\section{MOLECULAR CHARACTERIZATION AND GENETIC DIVERSITY OF DIFFERENT VARIETIES OF AVOCADO BY MICROSATELLITES MARKERS (SSR)}

\begin{abstract}
Belonging to Lauraceae family, avocado vegetables include three races: West Indian, Guatemalan and Mexican. Molecular markers are a fast and efficient tool for genomic studies since they detect polymorphism directly at the DNA level and do not suffer any kind of environmental influence. Based on this polymorphism, it is possible to make inferences about the relationship between genotype and phenotype of individuals, which ultimately will increase the efficiency of breeding programs. The objective of this study was to investigate the genetic diversity among seven varieties of avocados from five loci of microsatellite molecular markers (SSR). In samples of avocado evaluated it was found a total of 18 alleles, with an average of 3.6 alleles per locus. The dendrogram generated from UPGMA cluster analysis grouped separately from the rest of the genotypes the "Geada" cultivar an Antillean race, possibly because this strain is a pure race, the remainder was divided into two principal races groups, the Guatemalan and the Mexican. The genotypes of the seven varieties of avocado, show genetic diversity in the five loci of microsatellite molecular markers (SSR) assessed, indicating that they are promising materials for using in future breeding programs.
\end{abstract}

Index Terms: Persea americana, SSR, fingerprinting, germoplasm banks.

\footnotetext{
1'(Trabalho 172-10). Recebido em: 30-07-2010. Aceito para publicação em: 06-09-2011.

${ }^{2}$ Docente do Departamento de Produção Vegetal - Universidade Estadual Paulista (UNESP), Jaboticabal, SP. E-mail: baldo@fcav.unesp.br ${ }^{3}$ Eng. Agra. Mestranda - Universidade Estadual Paulista (UNESP), Jaboticabal-SP. Bolsista FAPESP. E-mail: gabrielafontanetti@hotmail.com ${ }^{4}$ Bióloga. Mestranda- Universidade Estadual Paulista (UNESP), Jaboticabal-SP. E-mail: deiserpaula@yahoo.com.br ${ }_{5}^{5}$ Biólogo. Mestrando- Universidade Estadual Paulista (UNESP), Jaboticabal-SP. E-mail: heliojunq@hotmail.com

${ }^{6}$ Eng. Agr.Mestre em Agronomia. Doutorando- Universidade Estadual Paulista (UNESP), Jaboticabal-SP. E-mail: flavionex@hotmail.com ${ }^{7}$ Docente da Fundação Educacional de Andradina, Andradina, SP. E-mail: kitty_petrarolha@yahoo.com.br
} 


\section{INTRODUÇÃO}

A cultura do abacateiro possui expressiva importância no cenário internacional e nacional, sendo o Brasil considerado o quarto produtor mundial dessa fruta, com uma produção de 169 mil toneladas colhidas, atrás apenas do México, Indonésia e Colômbia (FAO, 2008). É cultivado em quase todos os Estados do Brasil, sendo uma das frutíferas mais produtivas por unidade de área cultivada (TANGO; TURATTI, 1992). O Estado de São Paulo destaca-se como o maior produtor brasileiro, com 4.560 ha e uma produção de 91.981 toneladas (IBRAF, 2006).

Pertencente à família Lauraceae, subgênero Persea, o abacate compreende três raças com distintas exigências climáticas com referência ao fator térmico: Antilhana, Guatemalense e Mexicana (Zoneamento agrícola do Estado de São Paulo, 2010).

Para o desenvolvimento da cultura, com ganhos significativos de produtividade e qualidade de frutos, o melhoramento genético torna-se uma ferramenta fundamental; sendo primordial, para tanto, a existência de variabilidade genética (LEITE, 2010).

A conservação ex situ de germoplasma realizada em Bancos Ativos de Germoplasma (BAG) permite manter e garantir a disponibilidade de materiais essenciais aos programas de melhoramento genético. Um BAG tem um papel fundamental na preservação da variabilidade genética, sendo fundamental a manutenção de acessos (GOEDERT, 2007).

Os marcadores moleculares são uma ferramenta rápida e eficaz para estudos genômicos, uma vez que detectam o polimorfismo diretamente ao nível do DNA sem influência ambiental (SOUZA, 2001). Com base nesse polimorfismo, é possível fazer inferências sobre as relações entre o genótipo e o fenótipo dos indivíduos, o que em última análise permite aumentar a eficiência dos programas de melhoramento.

Entre as diferentes classes de marcadores moleculares, os microssatélites, também denominadas SSR (Simple Sequence Repeat), são os preferidos para aplicações e estudos genéticos no melhoramento de plantas, principalmente devido a sua natureza multialélica, herança codominante e transferibilidade entre espécies (DECROOCQ et al., 2003;), facilidade de detecção pela PCR, abundância relativa e cobertura extensiva do genoma (LI et al., 2002) e necessidade de quantidades pequenas de DNA para dar início às reações (POWELL et al., 1996). Além disso, também exibem altas taxas de mutação (VIGOROUX et al., 2002) e associação preferencial com regiões não repetitivas do genoma (MORGANTE et al., 2002), o que os fazem bastante úteis em estudos de diversidade genética de frutíferas como mamão (OLIVEIRA et al., 2008); mirtilo (SILVA et al., 2008); acerola (SALLA et al., 2002), maçã (SZEWC-MCFADDEN et al., 1996) e o próprio abacate (LAVI et al., 1994; SHARON et al., 1997; BORRONE et al., 2009).

Diante do exposto, o objetivo do presente trabalho foi investigar a diversidade genética entre sete variedades de abacate do Banco de Germoplasma da FCAV/UNESP, a partir de 5 lócus de marcadores moleculares microssatélites (SSR) para a preservação da variabilidade genética e manutenção dos acessos.

\section{MATERIAL E MÉTODOS}

O estudo foi realizado na Área Experimental de Produção de Mudas Frutíferas do Departamento de Produção Vegetal da Faculdade de Ciências Agrárias e Veterinárias (FCAV/UNESP), Câmpus de Jaboticabal-SP, utilizando-se de sete variedades de abacate, pertencentes ao Banco de Germoplasma da referida instituição de ensino e pesquisa: variedades-copa brasileira Margarida, Geada e Fortuna; variedade-copa americana Hass; variedade-copa mexicana Fuerte e porta-enxertos Toro Canyon e Duke 7, apresentando, estas duas últimas, aroma de anis nas folhas, característica da raça Mexicana.

Folhas novas e sadias foram coletadas, identificadas e acondicionadas em caixas térmicas com gelo, e transportadas ao Laboratório de Bactérias e Biotecnologia Aplicada do Departamento de Biologia Aplicada à Agropecuária da FCAV/UNESP - Câmpus de Jaboticabal - SP), onde foram armazenadas em freezer $\left(-80^{\circ} \mathrm{C}\right)$. A extração de DNA das 7 variedades de abacate foi efetuada com base na metodologia descrita por Lodhi e colaboradores (1994). Após a extração, o DNA foi quantificado, utilizando a técnica de eletroforese em gel de agarose $0,8 \%$, em TEB $1 \mathrm{X}$ (Tris $28 \mathrm{mM}$, ácido bórico $88 \mathrm{mM}$, EDTA $7 \mathrm{mM}, \mathrm{pH}$ $8,3)$ contendo brometo de etídio $(5 \mu \mathrm{g} / \mathrm{mL})$.

Para as análises dos lócus, procedeu-se à amplificação de regiões de microssatélites (SSR) utilizando cinco pares de primers, concedidos pela empresa Uniscience Tecnologis sendo estes descritos na TABELA 1. A reação de amplificação de volume de 15 uL foi constituída de tampão PCR (1X), $0,1 \mathrm{mM}$ de cada dNTP, $2 \mathrm{mM}$ de $\mathrm{MgCl}_{2}, 1 \mathrm{uM}$ de cada integrante do par de primer (F e R), 2 unidades de Taq DNA polimerase, 18 ng de DNA genômico. As reações de amplificação foram realizadas nas se- 
guintes condições: $3 \min$ a $94^{\circ} \mathrm{C}$ (desnaturação), 30 s a $94^{\circ} \mathrm{C}, 1 \mathrm{~min}$ à temperatura de anelamento de cada par de primer (TABELA 1$), 1 \mathrm{~min}$ a $72^{\circ} \mathrm{C}, 35 \mathrm{x}(30 \mathrm{~s}$ a $94^{\circ} \mathrm{C}, 1 \mathrm{~min}$ à temperatura de anelamento de cada par de primer, 1 min a $72^{\circ} \mathrm{C}$ ) e $10 \min$ a $72^{\circ} \mathrm{C}$ (extensão).

Os produtos de amplificação foram separados em géis de agarose a 3\%, em corrida com TBE (1X) com tensão constante de $110 \mathrm{~V}$, conforme procedimento já descrito. Para estimar o tamanho dos fragmentos amplificados (alelos), foi utilizado um padrão de tamanho molecular 100 pb e $1 \mathrm{~Kb}$ laeder (Fermentas) na mesma corrida eletroforética.

Para a avaliação da diversidade genética existente entre os genótipos de abacateiro, foram calculados: o número de alelos e as respectivas frequências nos lócus SSR (AVAG13, AVAG25, AVAG10, AVAG11, AVAG06). A partir destas frequências, calcularam-se, para todos os possíveis pares de genótipos, as distâncias genéticas de Roger (1972) modificada por Wright (1978), as quais foram empregadas para o agrupamento dos genótipos pelo método UPGMA (Unweighted Pair-Group Method, Arithimetical Means). Nestas análises, utilizou-se software Tools for Population Genetics Analyses (TFPGA) versão 1.3 (MILLER, 1997).

\section{RESULTADOS E DISCUSSÃO}

Nas amostras de abacateiros avaliadas, encontrou-se um total de 18 alelos, com uma média de 3,6 alelos por lócus. A maior diversidade alélica observada foi no lócus AVAG13, com 6 alelos distintos, e a menor no lócus AVAG25, com apenas dois alelos. Os lócus AVAG25 e AVAG11 foram os que apresentaram o maior número de indivíduos homozigotos, enquanto maior nível de heterozigosidade foi observada no lócus AVAG06.

A heterozigosidade média observada foi de 0,5637, com valor mínimo de 0,3367 e máximo de 0,7500 , sendo todos os cinco lócus polimórficos (critério de 99\%), como pode ser observado na Tabela 2 , o que está de acordo com os resultados encontrados por Ashworth e Clegg (2003), que encontraram a média de 0,6070 de heterozigosidade entre 35 cultivares de abacate.

A distância genética média entre todos os genótipos foi de 0,60429 , variando entre 0,8660 entre os genótipos 5 e 6 e 0,3536 entre os genótipos 4 e 7, podendo ser observados na Tabela 3. Dada a dificuldade de se encontrar literatura pertinente com esta cultura, passa-se a discutir com base entre outras fruteiras. Os valores aqui encontrados estão de acordo com os resultados de Amorin et al. (2009) que, estimando a divergência genética entre 38 diploides de banana do programa de melhoramento da Embrapa Mandioca e Fruticultura Tropical, incluindo genótipos melhorados, cultivados e selvagens, por meio de 15 marcadores microssatélites, observaram uma similaridade genética média de 0,44 , variando de 0,29 a 0,60 .

Silva et al. (2008), caracterizando 8 genótipos de mirtilo do programa de melhoramento da Embrapa Clima Temperado, com a utilização de 3 pares de primers do tipo microssatélites, obtiveram similaridade genética entre as cultivares variando de 25 a $75 \%$, com similaridade média $(42,4 \%)$. Os autores obtiveram três grupos, revelando a eficiência da técnica de microssatélite na caracterização de genótipos dessa espécie.

Cinco marcadores microssatélites (SSR) foram utilizados objetivando a caracterização molecular de 29 porta-enxertos de pêssego, os quais permitiram a separação dos mesmos em subgrupos correspondentes aos subgêneros a que pertencem, Prunophora e Amygdalus, revelando a eficiência da técnica para essa espécie (BIANCHI et al., 2004).

Santos et al. (2010), trabalhando com cultivares de mangueira, observaram que, dos 94 indivíduos analisados com apenas três marcadores microssatélites, $83 \%$ foram identificados como híbridos.

A formação dos agrupamentos demonstra a existência de dois grupos: um formado pela maioria dos genótipos $(1 ; 2 ; 3 ; 4 ; 6$ e 7$)$ e um composto apenas pelo genótipo 5 , portanto o que apresenta maior diferença entre todos, como mostra a Figura 1. Rodriguez et al. (2007) avaliaram 17 genótipos de uma coleção de germoplasma de abacate cubano e concluíram que os marcadores microssatélites foram os que detectaram os níveis mais altos de heterozigosidade.

Os dois grupos discriminados pelo dendrograma gerado a partir de análise de agrupamento UPGMA com base no índice de similaridade de Roger (1972), modificada por Wright (1978), foram: um formado pela variedade Geada, possivelmente por esta variedade ser uma raça pura, e outro grande grupo formado pelas demais variedades, como pode ser observado na Figura 1.

Este grande grupo pode ser dividido em dois subgrupos. No subgrupo superior do dendrograma, encontramos as cultivares Margarida (híbrido proveniente do cruzamento entre as raças antilhana e guatemalense), Fortuna (híbrido proveniente do cruzamento entre as raças antilhana e guatemalense) 
e Fuerte (híbrido proveniente do cruzamento entre as raças mexicana e guatemalense).

O segundo subgrupo contém as cultivares Duke 7 e o Toro Canyon, ambos ditos como sendo da raça mexicana. Entretanto, nesse grupo, houve o agrupamento da cultivar Hass, que por sua vez é considerada como guatemalense. De acordo com Donadio (1995), a variedade Hass é a principal variedade do grupo floral tipo $\mathrm{A}$, destinada à exportação. Surgiu na década de 20, na Califórnia, e foi selecionada a partir da raça guatemalense, porém apresenta indícios de que se trata de um híbrido do cruzamento com a raça mexicana.

Cuiris-Pérez et al. (2009) avaliaram 77 acessos de um banco de germoplasma e observaram a segregação dos indivíduos em dois grandes grupos dentro dos acessos mexicanos e concluíram que o polimorfismo encontrado pelos microssatélites indicou alta variação genética existente dentro dos acessos da Raça Mexicana. Schnell et al. (2003) avaliaram 224 acessos da National Germoplasm Repository em Miami, com 14 lócus (incluindo os 5 avaliados neste trabalho) e agruparam, também, as raças em dois grandes grupos: Guatemalense e Mexicana.

TABELA 1 - Sequências e temperatura de anelamento dos 5 pares de primers SSR de abacate.

\begin{tabular}{ccccc}
\hline Locus & Referência & Forward (5`-3`) & Reverse (5`-3`) & $\mathrm{T}^{\circ} \mathrm{C}$ \\
\hline AVAG06 & Sharon et al. (1997) & CGACCTCTTCTTATACTC & GTACCTCTGATAATGAGCAT & 40 \\
AVAG10 & Sharon et al. (1997) & GAATTACAAAGCACTAGAG & GTAGAAAGTGGGCACACAT & 45 \\
AVAG11 & Sharon et al. (1997) & AGCGATGAACATTACCA & ATTTCTTCAACCCATCTGTC & 50 \\
AVAG13 & Sharon et al. (1997) & TGCGATAACAACTGGAC & AACTAGGACCTGAAACCG & 50 \\
AVAG25 & Sharon et al. (1997) & ATGGTTTTTTCCTGCCCTTT & AACAAGCCCCCTAAAAGAA & 50 \\
\hline
\end{tabular}

TABELA 2- Níveis de heterozigosidade observados em genótipos de abacateiro.

\begin{tabular}{cc}
\hline Lócus & Heterozigosidade $(\mathrm{He})$ \\
\hline AVAG13 & 0,6837 \\
AVAG25 & 0,3367 \\
AVAG10 & 0,6400 \\
AVAG11 & 0,4082 \\
AVAG06 & 0,7500 \\
\hline
\end{tabular}

TABELA 3- Matriz de distância genética entre genótipos de abacateiro.

\begin{tabular}{llrllllll}
\hline \multicolumn{10}{c}{ GENÓTIPOS } \\
\hline & 1 & 2 & 3 & 4 & 5 & 6 & 7 \\
1 & $* * * * *$ & & & & & & & \\
2 & 0,6708 & $* * * * *$ & & & & & & \\
3 & 0,4472 & 0,6325 & $* * * * *$ & & & & & \\
4 & 0,5916 & 0,5000 & 0,5000 & $* * * * *$ & & & & \\
5 & 0,7906 & 0,7071 & 0,7500 & 0,6124 & $* * * * *$ & & & \\
6 & 0,4330 & 0,5000 & 0,6124 & 0,6124 & 0,8660 & $* * * * *$ & & \\
7 & 0,6124 & 0,7071 & 0,5000 & 0,3536 & 0,6455 & 0,6455 & $* * * * *$ & \\
\hline
\end{tabular}



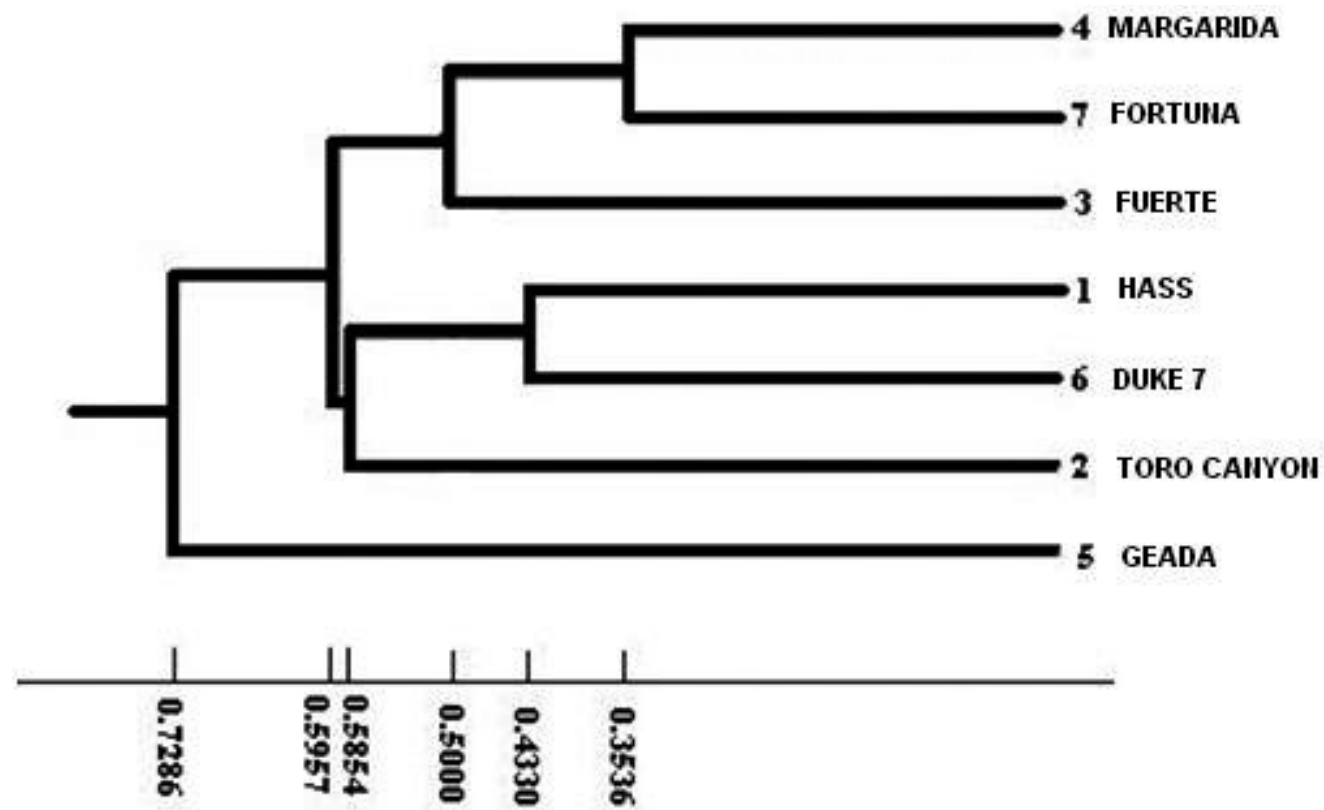

FIGURA 1- Similaridade genética entre sete genótipos de abacate, obtida a partir do coeficiente de Roger (1972), modificado de Wright (1978), com base nos marcadores moleculares microssatélites, com o uso do método UPGMA.

\section{CONCLUSÕES}

1-Os genótipos das sete variedades de abacate, pertencentes ao Banco de Germoplasma da FCAV/UNESP, apresentam diversidade genética nos cinco lócus de marcadores moleculares microssatélites (SSR) avaliados.

2- Os marcadores microssatélites são eficientes na caracterização de genótipos de abacate.

3- Pretende-se, em um futuro próximo, avaliar um maior número de amostras dentro de cada variedade, para verificar se este comportamento de diversidade se mantém.

\section{REFERÊNCIAS}

AMORIM, E.P.; LESSA, L. S.; LEDO, C. A. S.; AMORIM, V. B. de O.; REIS, R. V.; SANTOSSEREJO, J. A.; SILVA, S. O. Caracterização agronômica e molecular de genótipos diploides melhorados de bananeira. Revista Brasileira de Fruticultura, Jaboticabal, v. 31, n.1, p. 154-161, 2009.
ASWORTH, V.E.T.M.; CLEGG, M.T. Microssatelite markers in avocado (Persea americana Mill.): Genealogical relationships among cultivated avocado genotypes. Journal of Heredity, Washington, v. 94 , n. 5, p. 407-415, 2003.

BIANCHI, V.J.; SANSAVINI, S.; FACHINELLO, J.C. Identificação de porta-enxertos de Prunus spp. Com marcadores microssatélites. Scientia Agrícola, Piracicaba, v. 61, n. 3, 2004.

BORRONE, J.W.; BROWN, J.S.; TONDO, C.L.; MAURO-HERRERA, M.; KUHN, D.N.; VIOLI, H.A.; SAUTTER, R.T.; SCHNELL, R.J. An ESTSSR-based linkage map for Persea americana Mill. (avocado). Tree Genetics \& Genomes, Berlin, v. 5, n. 4, p. 553-560, 2009.

CUIRIS-PÉREZ, H.; GUILLÉN-ANDRADE, H.; PEDRAZA-SANTOS, M.E.; LÓPEZ-MEDINA, J.; VIDALES-FERNÁNDEZ, I. Genetic variability within mexican race avocado (Persea americana Mill.) germplasm collections determined by ISSRs. Revista Chapingo. Serie Horticultura, Chapingo, v. 15, n. 2, p. 169-175, 2009. 
DECROOCQ, V.; FAVÉ, M.; HAGEN, L.; BORDENAVE, L.; DECROOCQ, S. Development and transferability of apricot and grape EST microsatellite markers across taxa. Theoretical and Applied Genetics, Berlin, v.106, p. 912-922, 2003.

DONADIO, L. C. Abacate para exportação: aspectos técnicos da produção. 2. ed. rev. aum.. Brasília: EMBRAPA-SPI, 1995. p. 53. (Publicações Técnicas FRUPEX, 2)

FAO - Food Agricultural Organization. Statistics database. Disponível em: <www.apps.fao.org $>$. Acesso em: 27 jun. 2008.

GOEDERT, C.O. Histórico e avanços em recursos genéticos no Brasil. In: NASS, L.L. (Ed.). Recursos genéticos vegetais. Brasília: Embrapa, 2007. p. 23-60.

IBRAF - Instituto Brasileiro de Fruticultura. Disponível em: <www.ibraf.org.br>. Acesso em: 14 set. 2006 .

LAVI, U.; AKKAYA, M.; BHAGWAT, A.; LAHAV, E.; CREGAN, P.B. Methodology of generation and characteristics of simple sequence repeat DNA markers in avocado (Persea Americana M.). Euphytica, Wageningen, v.80, p.171-177, 1994.

LEITE, J.B.V. Coleções de fruteiras e sua importância para o melhoramento genético. Disponível em: $<$ www.todafruta.com.br $>$. Acesso em: 02 jul. 2010 .

LI, Y.C.; KOROL, A.B.; FAHIMA, T.; BEILES, A.; NEVO, E. Microsatellites: genomic distribution, putative functions and mutational mechanisms: a review. Molecular Ecology, Osford, v.11, p.24532465, 2002.

LODHI, M.A.; YE, G.N.; WEEDEN, N.F.; REISCH, B.I. A simple and efficient method for DNA extraction from grapevine cultivars and Vitis species. Plant Molecular Biology Reporter, Dordrecht, v.12, n.1, p.6-13, 1994.

MILLER, M.P. Tools for population genetic analysis (TGFPA). 1.3. A Windows program for the analysis of allozime and molecular population genetic data. Computer software distributed by the author. 1997.
MORGANTE, M.; HANAFEY, M.; POWELL, W. Microsatellites are preferentially associated with nonrepetitive DNA in plant genomes. Nature Genetics, New York, v.30, p.194-200, 2002.

OLIVEIRA, E. J.; DANTAS, J. L. L.; CASTELLEN, M.S.; MACHADO, M. D. Identificação de microssatélites para o mamoeiro por meio da exploração do banco de dados de DNA. Revista Brasileira de Fruticultura, Jaboticabal, v. 30, n.3, p. 841-845, 2008.

POWELL, W.; MACHRAY, G.C.; PROVAN, J. Polymorphism revealed by simple sequence repeats. Trends in Plant Science, Oxford, v.1, p. 215-221, 1996.

RODRÍGUEZ, N. N.; FUENTES, J. L.; COTO, O.; FUENTES, V. R.; RAMÍREZ, I. M.; BECKER, D.; RODRÍGUEZ, I.; GONZÁLEZ, C.; XIQUÉS, S.; ROMÁN, M. I.; VELÁZQUEZ, B.; RHODE, W.; JIMÉNEZ, N. Comparative study of polymorphism level, discrimination capacity and informativeness of AFLP, ISTR, SSR and Isoenzymes markers and agro-morphological traits in avocado. In: WORLD AVOCADO CONGRESS, 6., 2007, Viña del Mar, Chile. Proceedings... v. 76, p.12-16.

ROGERS, J.S. Measures of genetic similarity and genetic distance: studies in genetics. Austin: University of Texas, 1972. p. 145-154. (Publication, 7213)

SALLA, M. F. S.; RUAS, C. F.; RUAS, P. M.; CARPENTIERI-PIPOLO, V. Uso de marcadores moleculares na análise da variabilidade genética em acerola (Malpighia emarginata D.C.). Revista Brasileira de Fruticultura, Jaboticabal, v. 24, n.1, p.15-22, 2002.

SANTOS, C.A.F.; LIMA FILHO, J.M.P.; LIMA NETO, F.P. Estratégias para o desenvolvimento de novas cultivares de mangueira para o semiárido brasileiro. Revista Brasileira de Fruticultura, Jaboticabal, v.32, n.2, p. 493-497, 2010.

SCHNELL, R. J.; BROWN, J. S.; OLANO, C. T.; POWER, E. J.; KROL, C. A.; KUHN, D. N.; MOTAMAYOR, J. C. Evaluation of avocado germplasm using microsatellite markers. Journal of the American Society for Horticultural Science, Alexandria, v.128, p. 881-889, 2003. 
SHARON, D; CREGAN, PB.; MHAMEED S, KUSHARSKA K, HILLEL J, LAHAV E, LAVI U. An integrated genetic linkage map of avocado. Theoretical and Applied Genetics, Berlin, v.95, p.911-921, 1997.

SILVA, S. D. A.; ANTUNES, L. E. C.; ANTHONISEN, D. G.; LEMÕES, J. S.; GONÇALVES, E. D. Caracterização de genótipos de mirtilo utilizando marcadores moleculares. Revista Brasileira de Fruticultura, Jaboticabal, v.30, n.1, p.180-184, 2008.

SOUZA, A.P. Biologia molecular aplicada ao melhoramento. In: NASS, L.L.; VALOIS, A.C.C.; MELLO, I.S.; VALADARES-INGLIS, M.C. (Ed.). Recursos genéticos e melhoramento de plantas. Rondonópolis: Fundação, 2001. p.939-965.

SZEWC-MCFADDEN, A.K.; LAMBOY, W.F.; HOKANSON, S.C.; MCFERSON, J.R. Utilization of identified simple sequence repeats (SSRs) in Malus x Domestica (apple) for germplasm characterization. Horticultural Science, London, v.31, p.619, 1996.
TANGO, J. S.; TURATTI, J. M. Óleo de abacate. In: ITAL. Abacate: cultura, matéria- prima, processamento e aspectos econômicos. Campinas, 1992. p. 156-192.

VIGOUROUX, Y.; JAQUETH, J.S.; MATSUOKA, Y.; SMITH, O.S.; BEAVIS, W.D.; SMITH, J.S.C.; DOEBLEY, J. Rate and pattern of mutation at microsatellite loci in maize. Molecular Biology, New York, v.19, p.1251-1260, 2002.

ZONEAMENTO AGRÍCOLADO ESTADO DE SÃO PAULO. Aptidão ecológica da cultura do abacate. Disponível em: $\leq$ http: www.ciiagro.sp.gov.br $>$. Acesso em: out. 2010.

WRIGHT, S. Evolution and the genetics of populations: variability within and among natural populations. Chicago: Universty of Chicago Press, 1978. v. 4 , p. 588 . 